\title{
Perfil da violência contra a pessoa idosa na cidade do Recife-PE
}

\author{
Profile of violence against the elderly in the city of Recife-PE, Brazil
}

\section{Resumo}

Objetivo: Descrever o perfil da violência contra a pessoa idosa na cidade do RecifePE. Metodologia: Estudo descritivo de corte transversal, realizado no período de 20092012 na cidade do Recife-PE. Os dados foram obtidos do Sistema VIVA, que faz parte do Sistema de Informação de Agravos de Notificação (Sinan-Net); as variáveis foram apresentadas conforme a Ficha de Notificação/Investigação Individual de Violência Doméstica, Sexual e/ou Outras Violências. Resultados: Foram estudados 242 casos; a maior parte das vítimas era do sexo feminino $(59,00 \%)$, tendo como agressor predominantemente o filho do sexo masculino. A violência física foi a forma de agressão mais observada $(44,96 \%)$, ocorrida, principalmente, nas residências $(47,52 \%)$. Conclusão: Observou-se incremento na notificação de casos de violência contra a pessoa idosa; o perfil epidemiológico mais frequente dessa violência na cidade do Recife é semelhante ao apresentado pela literatura, em que as vítimas são do sexo feminino, pardas e sofreram violência física em sua residência perpetrada pelo filho do sexo masculino. Espera-se, com este estudo, auxiliar a construção de uma rede de proteção que impacte positivamente na redução dos casos de violência contra a pessoa idosa.

\section{Abstract}

Objective: To describe the profile of violence against the elderly and factors associated with such violence in Recife-PE, Brazil. Methodology: A cross-sectional descriptive study in years 2009-2012 conducted in the city of Recife-PE. Data were obtained from the System VIVA, which is part of the Information System for Notifiable Diseases (SinanNet); variables were show according to the Notification / Investigation Individual Formulary of Domestic, Sexual and/or Other Types of Violences. Results: 242 occurrences were studied, most of the victims were female (59.00\%), and the aggressor was predominantly the son. Physical violence was the most frequently observed form of aggression (44.96\%), which occurred mainly in the home (47.52\%). Conclusion: There was an increase in the reporting of cases of violence against the elderly, the most common

Palavras-chave: Violência. Idoso. Epidemiologia.

Key words: Violence. Elderly. Epidemiology.

\footnotetext{
Universidade de Pernambuco, Programa de Residência Multiprofissional de Saúde Coletiva. Recife, PE, Brasil.

2 Secretaria Municipal de Saúde, Coordenação de Prevenção de Acidentes e Violência. Recife, PE, Brasil. 
epidemiological profile of this violence in the city of Recife is similar to that presented in the literature, where the victims are female, brown and suffered physical violence in their residence perpetrated by male child. It is hoped that this study help build a safety net that will impact positively on the reduction of cases of violence against the elderly.

\section{INTRODUÇÃO}

O envelhecimento da população mundial é um fato concreto e de conhecimento público. O Brasil se encontra no processo de transição demográfica, seguindo o padrão mundial: o aumento do número de pessoas idosas com possibilidade de atingir elevadas faixas etárias, ${ }^{1,2}$ o que remete à necessidade de preservação da qualidade de vida na terceira idade. ${ }^{3} \mathrm{O}$ perfil do crescimento populacional atual exige preparação cuidadosa, em especial das áreas de saúde, mobilidade e assistência social. É fundamental ter serviços, pessoas preparadas, equipamentos e recursos, dentro de uma concepção de promoção, prevenção e assistência. ${ }^{2} \mathrm{O}$ fenômeno do envelhecimento populacional desencadeou um processo denominado como "elevação da consciência sobre os direitos das pessoas idosas", despertando a sociedade para a questão do abuso às pessoas idosas e aumentando a responsabilidade do estado. ${ }^{4}$

A Lei $\mathrm{n}^{\mathrm{o}}$ 8.842/94 (Política Nacional do Idoso $)^{5}$, o Decreto $\mathrm{n}^{\mathrm{o}} 1.948 / 96^{6}$ e a Lei $\mathrm{n}^{\circ}$ 10.741/03 (Estatuto do Idoso) ${ }^{7}$ são exemplos das diversas legislações em defesa da pessoa idosa. O Estatuto do Idoso, ${ }^{7}$ mais recente das leis, preconiza ações concretas mais organizadas para o enfrentamento da violência contra essa população, determinando que nenhuma pessoa idosa poderá ser objeto de negligência, discriminação, violência, crueldade ou opressão. ${ }^{8}$

A codependência física e/ou emocional causada pelo processo de envelhecimento pode acabar ocasionando conflitos que ocorrem no âmbito familiar, institucional e no convívio social. Nessas situações, é comum acontecer o fenômeno da violência contra a pessoa idosa. ${ }^{?}$

A Organização Mundial da Saúde define a violência contra a pessoa idosa como qualquer ato, único ou repetitivo, ou omissão, que ocorra em qualquer relação supostamente de confiança, que cause dano ou incômodo. ${ }^{10} \mathrm{~A}$ violência é um fenômeno social, histórico, complexo, multicausal e em rede, podendo se manifestar na sociedade de várias formas. As violências ocorrem em todas as culturas, sociedades, etnias e em todos os níveis sociais de todos os países do mundo. ${ }^{11,12}$ As consequências que a violência causa para a saúde do indivíduo, da sua família e da sociedade fazem com que esse agravo seja considerado um problema de saúde pública, com alto custo emocional e social. ${ }^{10}$

As violências e os maus-tratos contra as pessoas idosas se referem aos abusos: 1) físicos: correspondem ao uso de força física que pode resultar completamente em dano, dor ou prejuízo físico a pessoa idosa; 2) psicológicos: dizem respeito às agressões verbais ou gestuais cometidas com o objetivo de aterrorizar, rejeitar, humilhar, restringir a liberdade ou ainda isolar a pessoa idosa do convívio social; 3) sexuais: consistem em práticas eróticas e sexuais não consensuais contra uma pessoa idosa; 4) financeiros: referem-se ao uso ilegal ou impróprio dos bens da pessoa idosa; 5) negligências: representadas pela recusa, omissão ou fracasso por parte do responsável no cuidado com a pessoa idosa; e 6) autonegligências: consistem no comportamento de uma pessoa idosa que ameaça sua própria saúde ou segurança. ${ }^{1,2,13}$

Os profissionais de saúde têm papel importante na luta contra violências às pessoas idosas, uma vez que os serviços de saúde em geral, e mais particularmente os setores de emergência e ambulatórios, constituem uma das principais portas de entrada das vítimas de maus-tratos. ${ }^{14}$

Dada sua importância como problema de saúde pública, a violência contra a pessoa idosa 
tornou-se objeto de vigilância epidemiológica no Brasil a partir de 2006, por meio da implantação do Sistema de Vigilância de Violências e Acidentes (VIVA). ${ }^{15}$ Este atende ao que determina a Lei $\mathrm{n}^{\circ}$ 12.461/2011, a qual ressalta a obrigatoriedade da notificação dos serviços de saúde públicos e privados à autoridade sanitária nos casos de suspeita ou confirmação de violência praticada contra a pessoa idosa. ${ }^{16}$ A notificação não é uma denúncia, mas uma ferramenta que promove políticas públicas que reduzam os riscos e danos associados às violências contra as pessoas idosas. Com base nessa notificação, torna-se possível conhecer as formas de violência, suas vítimas e agressores; identificar os serviços da rede; realizar o encaminhamento para a rede de proteção; desenvolver ações de prevenção à violência; e promover assistência adequada às vítimas de agressão. ${ }^{17}$

Tendo em vista a transição demográfica atual e a magnitude do problema da violência praticada contra a pessoa idosa, este estudo teve como objetivo descrever o perfil da violência contra a pessoa idosa na cidade do Recife-PE, para que se possa conhecer melhor a situação da violência enfrentada por essa população e promover ações que impactem na qualidade de vida dessa população.

\section{METODOLOGIA}

O artigo se refere a um estudo descritivo de corte transversal na cidade do Recife, capital de Pernambuco, situado na Região Nordeste do Brasil. Foram incluídos no estudo todos os casos notificados de violência interpessoal (violência perpetrada por familiares ou desconhecidos contra uma ou poucas pessoas) e autoprovocada (perpetrada contra si próprio) em indivíduos com idade de 60 anos ou mais. Não foi excluído nenhum caso.

Os dados foram solicitados à Secretaria Municipal de Saúde do Recife, que concedeu anuência para a realização do estudo. Essas informações foram obtidas por meio do Sistema VIVA, que faz parte do Sistema de Informação de Agravos de Notificação (Sinan-Net). Os dados são referentes aos casos notificados no período entre 2009 e 2012.

Para a análise, foram utilizadas as variáveis presentes naFicha deNotificação/Investigação de Violência Doméstica, Sexual e Outras Violências, referentes a sexo, etnia, escolaridade, situação conjugal, presença de deficiência/transtorno, local de ocorrência, se ocorreu outras vezes, tipo de violência (física, psico/mental, tortura, sexual, financeira/econômica, negligência/ abandono, autoprovocada e outras), vínculo/grau de parentesco do agressor com a vítima, sexo do agressor, evolução do caso, encaminhamento no setor saúde e o encaminhamento para outros setores. A definição de todas as categorias dessas variáveis, inclusive os tipos de violência, encontrase disponível no instrutivo de notificação de violência doméstica, sexual e outras violências, elaborado pelo Ministério da Saúde. ${ }^{18}$ Ressaltase que mais de um tipo de violência e agressor poderia ser notificado em um mesmo sujeito.

Os dados foram apresentados sob forma de números absolutos e proporções derivadas das notificações de violências contra a pessoa idosa. Mantiveram-se os registros sem informação (em branco ou ignorado), visando apontar as carências ainda existentes no preenchimento dos dados de violência no Sinan-Net e que precisam ser conhecidas para a melhor qualidade dos dados.

Apesar de se tratar de estudo que utilizou dados secundários de agravo de notificação compulsória em território nacional, a pesquisa foi submetida ao Comitê de Ética em Pesquisa da Faculdade de Ciências Médicas de Pernambuco para apreciação, tendo sido aprovado segundo CAAE de no 19517713.7.0000.5192/13.

\section{RESULTADOS}

Foram registradas 242 notificações de violência contra a pessoa idosa na cidade do Recife-PE no Sinan-Net, no período de 2009 a 2012. Do total de casos notificados, 59,00\% referiam-se a vítimas do sexo feminino. Observou-se $1,46 \%$ do total das notificações no ano de 2009, passando para 3,37\% em 2012 (tabela 1). 
Tabela 1. Distribuição dos casos notificados da violência em pessoas idosas. Recife-PE, 2009-2012.

\begin{tabular}{|c|c|c|c|c|c|c|c|c|c|}
\hline \multirow[t]{2}{*}{ Ano } & \multicolumn{2}{|c|}{2009} & \multicolumn{2}{|c|}{2010} & \multicolumn{2}{|c|}{2011} & \multicolumn{2}{|c|}{2012} & \multirow[t]{2}{*}{ Total } \\
\hline & $\mathrm{M}$ & F & $\mathrm{M}$ & F & $\mathrm{M}$ & F & $\mathrm{M}$ & F & \\
\hline & 202 & 483 & 442 & 767 & 893 & 2.071 & 999 & 2.085 & \\
\hline Total & \multicolumn{2}{|c|}{685} & \multicolumn{2}{|c|}{1.209} & \multicolumn{2}{|c|}{2.964} & \multicolumn{2}{|c|}{3.084} & 7.942 \\
\hline $\begin{array}{l}\text { Casos em } \\
\text { pessoas idosas }\end{array}$ & \multicolumn{2}{|c|}{$\begin{array}{c}10 \\
(1,46 \%)\end{array}$} & \multicolumn{2}{|c|}{$\begin{array}{c}26 \\
(2,15 \%)\end{array}$} & \multicolumn{2}{|c|}{$\begin{array}{c}102 \\
(3,44 \%)\end{array}$} & \multicolumn{2}{|c|}{$\begin{array}{c}104 \\
(3,37 \%)\end{array}$} & 242 \\
\hline
\end{tabular}

Observou-se predomínio, em ambos os sexos, da etnia parda (46,69\%), seguida da branca com $18,18 \%$ dos casos. Com relação à escolaridade, a grande maioria dos casos foi ignorada $(80,17 \%)$ e $14,46 \%$ referiram ter até oito anos de estudo. Com relação à situação conjugal, 26,57\% do sexo feminino referiram ser viúvas, enquanto $24,24 \%$ do sexo masculino referiram ser casados. Porém, em ambos os sexos, a categoria "ignorado" apresentou maior número percentual (36,78\%). Dos casos notificados, $20,66 \%$ apresentaram deficiência/transtorno, sendo a deficiência física a mais prevalente para ambos os sexos com $32,00 \%$ dos casos (tabela 2 ). 
Tabela 2. Notificação de violência contra a pessoa idosa segundo variáveis sociodemográficas e de saúde, por sexo. Recife-PE, 2009-2012.

\begin{tabular}{|c|c|c|c|c|c|c|}
\hline \multirow{2}{*}{ Variáveis } & \multicolumn{2}{|c|}{ Feminino } & \multicolumn{2}{|c|}{ Masculino } & \multicolumn{2}{|c|}{ Total } \\
\hline & $\mathrm{n}$ & $\%$ & $\mathrm{n}$ & $\%$ & $\mathrm{n}$ & $\%$ \\
\hline \multicolumn{7}{|l|}{ Etnia/cor da pele } \\
\hline Branca & 30 & 20,98 & 14 & 14,14 & 44 & 18,18 \\
\hline Preta & 15 & 10,49 & 6 & 6,06 & 21 & 8,68 \\
\hline Parda & 68 & 47,55 & 45 & 45,45 & 113 & 46,69 \\
\hline Ignorado & 30 & 20,98 & 34 & 34,35 & 64 & 26,45 \\
\hline Total & 143 & 100,00 & 99 & 100,00 & 242 & 100,00 \\
\hline \multicolumn{7}{|l|}{ Escolaridade } \\
\hline Analfabeto & 2 & 1,40 & 3 & 3,03 & 5 & 2,07 \\
\hline$\leq 8$ anos de estudo & 23 & 16,08 & 12 & 12,12 & 35 & 14,46 \\
\hline Ensino médio completo & 3 & 2,10 & 1 & 1,01 & 4 & 1,65 \\
\hline Ensino superior completo & 3 & 2,10 & 1 & 1,01 & 4 & 1,65 \\
\hline Ignorado & 112 & 78,32 & 82 & 82,83 & 194 & 80,17 \\
\hline Total & 143 & 100,00 & 99 & 100,00 & 242 & 100,00 \\
\hline \multicolumn{7}{|l|}{ Situação conjugal } \\
\hline Solteiro & 26 & 18,18 & 12 & 12,12 & 38 & 15,70 \\
\hline Casado & 26 & 18,18 & 24 & 24,24 & 50 & 20,66 \\
\hline Viúvo & 38 & 26,57 & 9 & 9,09 & 47 & 19,42 \\
\hline Separado & 7 & 4,90 & 4 & 4,04 & 11 & 4,55 \\
\hline Não se aplica & 3 & 2,10 & 4 & 4,04 & 7 & 2,89 \\
\hline Ignorado & 43 & 30,07 & 46 & 46,47 & 89 & 36,78 \\
\hline Total & 143 & 100,00 & 99 & 100,00 & 242 & 100,00 \\
\hline \multicolumn{7}{|l|}{ Possui deficiência/transtorno } \\
\hline $\operatorname{Sim}$ & 34 & 23,78 & 16 & 16,16 & 50 & 20,66 \\
\hline Não & 58 & 40,56 & 27 & 27,27 & 85 & 35,13 \\
\hline Ignorado & 51 & 35,66 & 56 & 56,57 & 107 & 44,21 \\
\hline Total & 143 & 100,00 & 99 & 100,00 & 242 & 100,00 \\
\hline \multicolumn{7}{|l|}{ Tipo de deficiência/transtorno* } \\
\hline Física & 10 & 29,41 & 6 & 37,50 & 16 & 32,00 \\
\hline Mental & 5 & 14,71 & 3 & 18,75 & 8 & 16,00 \\
\hline Visual & 8 & 23,53 & 2 & 12,50 & 10 & 20,00 \\
\hline Auditiva & 6 & 17,65 & 2 & 12,50 & 8 & 16,00 \\
\hline Transtorno mental & 2 & 5,86 & 3 & 18,75 & 5 & 10,00 \\
\hline Transtorno comportamental & 1 & 2,94 & 0 & 0 & 1 & 2,00 \\
\hline Outros & 2 & 5,88 & 0 & 0 & 2 & 4,00 \\
\hline Total & 34 & 100,00 & 16 & 100,00 & 50 & 100,00 \\
\hline
\end{tabular}

*Um caso notificado pode ter mais de um tipo de deficiência/transtorno. Os percentuais foram calculados considerando o total de casos com deficiência/transtorno. 
O local mais relatado da ocorrência da violência foi a residência para ambos os sexos, com $47,52 \%$ dos casos. Na categoria "ocorreu outras vezes", $25,87 \%$ das mulheres foram as que mais relataram já ter sofrido violência anteriormente. Entretanto, em ambos os sexos, a categoria "ignorado" apresentou alto valor percentual, com 58,68\% do total de casos. A ocorrência de lesões autoprovocadas foi observada em 6,61\% dos casos notificados em ambos os sexos. $\mathrm{O}$ tipo de violência mais notificado foi a física, com 44,96\% dos casos, seguida pela negligência/ abandono, com $29,64 \%$, e a violência psicológica/ moral, com 13,36\% dos casos em ambos os sexos. Quanto ao agressor, o filho(a) foi o principal agressor, com 15,95\%, dos casos notificados. $\mathrm{Na}$ maioria dos casos notificados, o agressor era do sexo masculino (30,58\%), porém, nesta variável, $54,13 \%$ das notificações foram consideradas ignoradas (tabela 3).

Tabela 3. Notificação de violência contra pessoas idosas segundo variáveis da violência por sexo. Recife-PE, 2009-2012.

\begin{tabular}{|c|c|c|c|c|c|c|}
\hline \multirow{2}{*}{ Variáveis } & \multicolumn{2}{|c|}{ Feminino } & \multicolumn{2}{|c|}{ Masculino } & \multicolumn{2}{|c|}{ Total } \\
\hline & $\mathrm{n}$ & $\%$ & $\mathrm{n}$ & $\%$ & $\mathrm{n}$ & $\%$ \\
\hline \multicolumn{7}{|l|}{ Local de ocorrência } \\
\hline Residência & 86 & 60,14 & 29 & 29,29 & 115 & 47,52 \\
\hline Via pública & 12 & 8,39 & 13 & 13,13 & 25 & 10,33 \\
\hline Comércio/serviços & 4 & 2,80 & 3 & 3,03 & 7 & 2,89 \\
\hline Ignorado & 41 & 28,67 & 54 & 54,55 & 95 & 39,26 \\
\hline Total & 143 & 100,00 & 99 & 100,00 & 242 & 100,00 \\
\hline \multicolumn{7}{|l|}{ Ocorreu outras vezes } \\
\hline $\operatorname{Sim}$ & 37 & 25,87 & 10 & 10,10 & 47 & 19,42 \\
\hline Não & 34 & 23,78 & 19 & 19,19 & 53 & 21,50 \\
\hline Ignorado & 72 & 50,35 & 70 & 70,71 & 142 & 58,68 \\
\hline Total & 143 & 100,00 & 99 & 100,00 & 242 & 100,00 \\
\hline \multicolumn{7}{|l|}{ Lesão autoprovocada } \\
\hline $\operatorname{Sim}$ & 6 & 4,20 & 10 & 10,10 & 16 & 6,61 \\
\hline Não & 137 & 95,80 & 89 & 90,90 & 226 & 93,39 \\
\hline Total & 143 & 100,00 & 99 & 100,00 & 242 & 100,00 \\
\hline \multicolumn{7}{|l|}{ Tipo de violência* } \\
\hline Física & 67 & 35,08 & 71 & 61,22 & 138 & 44,96 \\
\hline Psicológica/moral & 34 & 17,80 & 7 & 6,03 & 41 & 13,36 \\
\hline Tortura & 2 & 1,05 & 2 & 1,72 & 4 & 1,30 \\
\hline Sexual & 13 & 6,81 & 0 & 0 & 12 & 4,23 \\
\hline Financeira/econômica & 8 & 4,19 & 1 & 0,86 & 9 & 2,93 \\
\hline Negligência/abandono & 63 & 32,98 & 28 & 24,14 & 91 & 29,64 \\
\hline Outros & 4 & 2,09 & 7 & 6,03 & 11 & 3,58 \\
\hline Total & 191 & 100,00 & 116 & 100,00 & 307 & 100,00 \\
\hline
\end{tabular}




\begin{tabular}{|c|c|c|c|c|c|c|}
\hline \multirow{2}{*}{ Variáveis } & \multicolumn{2}{|c|}{ Feminino } & \multicolumn{2}{|c|}{ Masculino } & \multicolumn{2}{|c|}{ Total } \\
\hline & $\mathrm{n}$ & $\%$ & $\mathrm{n}$ & $\%$ & $\mathrm{n}$ & $\%$ \\
\hline \multicolumn{7}{|l|}{ Agressor** } \\
\hline Cônjuge & 14 & 8,86 & 3 & 3,03 & 17 & 6,61 \\
\hline Ex-cônjuge & 3 & 1,90 & 1 & 1,01 & 4 & 1,56 \\
\hline Filho(a) & 29 & 18,35 & 12 & 12,12 & 41 & 15,95 \\
\hline $\operatorname{Irmão(a)~}$ & 4 & 2,53 & 1 & 1,01 & 5 & 1,95 \\
\hline Amigos/conhecidos & 7 & 4,43 & 10 & 10,10 & 17 & 6,61 \\
\hline Desconhecidos & 17 & 10,76 & 6 & 6,06 & 23 & 8,95 \\
\hline Cuidador(a) & 3 & 1,90 & 0 & 0 & 3 & 1,18 \\
\hline Própria pessoa & 4 & 2,53 & 4 & 4,04 & 8 & 3,11 \\
\hline Outros & 23 & 14,56 & 3 & 3,03 & 26 & 10,12 \\
\hline Ignorado & 54 & 34,18 & 59 & 59,60 & 113 & 44,96 \\
\hline Total & 158 & 100,00 & 99 & 100,00 & 257 & 100,00 \\
\hline \multicolumn{7}{|l|}{ Sexo do agressor } \\
\hline Masculino & 45 & 31,47 & 29 & 29,29 & 74 & 30,58 \\
\hline Feminino & 22 & 15,38 & 4 & 4,04 & 26 & 10,74 \\
\hline Ambos os sexos & 8 & 5,59 & 3 & 3,03 & 11 & 4,55 \\
\hline Ignorado & 68 & 47,56 & 63 & 63,64 & 131 & 54,13 \\
\hline Total & 143 & 100,00 & 99 & 100,00 & 242 & 100,00 \\
\hline
\end{tabular}

*Um caso notificado pode ter mais de um tipo de violência; ${ }^{* *}$ cada caso notificado pode ter tido mais de um tipo de agressor.

Grande parte dos casos notificados evoluiu com alta $(46,70 \%)$ e aproximadamente $15,70 \%$ dos casos foram a óbito por violência, com proporção maior no sexo masculino (21,21\%). Quanto ao encaminhamento das vítimas no setor saúde, $35,54 \%$ dos casos notificados evoluíram para internação hospitalar. Com relação ao encaminhamento para outros setores, as delegacias foram as principais categorias marcadas (tabela 4). 
Tabela 4. Notificação de violência contra pessoas idosas segundo evolução do caso e encaminhamentos à rede de atendimento, por sexo. Recife-PE, 2009-2012.

\begin{tabular}{|c|c|c|c|c|c|c|}
\hline \multirow{2}{*}{ Variáveis } & \multicolumn{2}{|c|}{ Feminino } & \multicolumn{2}{|c|}{ Masculino } & \multicolumn{2}{|c|}{ Total } \\
\hline & $\mathrm{n}$ & $\%$ & $\mathrm{n}$ & $\%$ & $\mathrm{n}$ & $\%$ \\
\hline \multicolumn{7}{|l|}{ Evolução do caso } \\
\hline Alta & 70 & 48,95 & 43 & 43,44 & 113 & 46,70 \\
\hline Evasão/fuga & 1 & 0,70 & 2 & 2,02 & 3 & 1,24 \\
\hline Óbito por violência & 17 & 11,89 & 21 & 21,21 & 38 & 15,70 \\
\hline Óbito por outras causas & 53 & 37,06 & 31 & 31,31 & 84 & 34,71 \\
\hline Ignorado & 2 & 1,40 & 2 & 2,02 & 4 & 1,65 \\
\hline Total & 143 & 100,00 & 99 & 100,00 & 242 & 100,00 \\
\hline \multicolumn{7}{|l|}{ Encaminhamento ao setor saúde } \\
\hline Ambulatorial & 30 & 20,98 & 16 & 16,16 & 46 & 19,01 \\
\hline Internação hospitalar & 52 & 36,36 & 34 & 34,34 & 86 & 35,54 \\
\hline Não se aplica & 21 & 14,69 & 12 & 12,12 & 33 & 13,64 \\
\hline Ignorado & 40 & 27,97 & 37 & 37,38 & 77 & 31,81 \\
\hline Total & 143 & 100,00 & 99 & 100,00 & 242 & 100,00 \\
\hline \multicolumn{7}{|l|}{ Encaminhamento para outros setores } \\
\hline Casa abrigo & 1 & 1,64 & 0 & 0 & 1 & 1,14 \\
\hline $\begin{array}{l}\text { Delegacia de atendimento } \\
\text { à mulher/DEAM }\end{array}$ & 17 & 27,86 & 0 & 0 & 17 & 19,32 \\
\hline Outras delegacias & 22 & 36,07 & 14 & 51,86 & 36 & 40,90 \\
\hline Ministério Público & 4 & 6,56 & 0 & 0 & 4 & 4,55 \\
\hline $\begin{array}{l}\text { Centro de Referência da Assistência } \\
\text { Social/CREAS-CRAS }\end{array}$ & 1 & 1,64 & 1 & 3,70 & 2 & 2,27 \\
\hline Instituto Médico Legal (IML) & 7 & 11,48 & 8 & 29,63 & 15 & 17,05 \\
\hline Outros & 9 & 14,75 & 4 & 14,81 & 13 & 14,77 \\
\hline Total & 61 & 100,00 & 27 & 100,00 & 88 & 100,00 \\
\hline
\end{tabular}




\section{DISCUSSÃO}

A violência contra a pessoa idosa é uma questão complexa, por sua dinâmica e fatores determinantes intrinsecamente ligados ao ambiente familiar, à relação entre vítima e autor da agressão e sua dependência. Para Minayo ${ }^{19}$ e Queiroz ${ }^{20}$ as limitações cognitivas e físicas, isolamento social, fragilidade nas relações familiares e histórico de violência familiar são situações de risco para a violência contra as pessoas idosas. Compreender esses fatores e atuar de forma qualificada para que esses casos sejam identificados e notificados pelos profissionais de saúde é tarefa fundamental para que medidas efetivas de prevenção sejam adotadas.

Os dados apresentados neste artigo refletem o esforço na implementação da notificação para subsidiar políticas públicas de prevenção à violência voltada para a terceira idade. $\mathrm{O}$ setor saúde tem se tornado protagonista, assumindo o compromisso de revelar e monitorar os casos notificados, contribuindo com a tomada de decisões pelos setores responsáveis.

É certo que atualmente existe maior conscientização para o problema social da violência contra as pessoas idosas. Entretanto, a subnotificação dos casos sobre os agravos gerados na terceira idade e a não divulgação pelos sistemas de informação pode facilitar o aumento da violência na sociedade. Alguns autores citam que o despreparo dos profissionais de saúde para investigar os casos e a infraestrutura deficiente de atendimento e fragilidade das redes de apoio são algumas razões para a subnotificação..$^{21,22,23}$

De acordo com os dados apresentados, o estudo mostra que a violência contra as pessoas idosas continua ainda subnotificada; porém, observou-se incremento das notificações pelos serviços de saúde do Recife, passando de 1,46\% em 2009 para 3,37\% em 2012. O pequeno número de casos notificados foi uma limitação deste estudo, prejudicando o real dimensionamento do atual problema.
$\mathrm{Na}$ presente pesquisa, o elevado percentual de ignorados nas categorias analisadas pode ter prejudicado a elaboração fidedigna do perfil da violência contra as pessoas idosas no Recife, destacando-se as categorias referentes à escolaridade da vítima, o agressor e o sexo do agressor, com 80,17\%, 43,96\% e 54,13\% dos casos, respectivamente.

O perfil identificado no presente estudo mostra que a maioria das vítimas são mulheres de cor parda, viúvas e com baixa escolaridade, corroborando estudos realizados por Souza, ${ }^{24}$ Santos ${ }^{25}$ e Mascarenhas, ${ }^{26}$ os quais reafirmam ser esses fatores preponderantes na produção da violência de gênero, e que a etnia/cor está associada às condições de vida e situações de pobreza.

De acordo com os dados coletados pelo estudo, das vítimas notificadas, 19,42\% referiram já terem sido violentadas anteriormente. Segundo a literatura, quando a denúncia da violência doméstica vem a ser feita, já ocorreram diversos episódios anteriores e tendem a ser repetitivos até que haja mudança no ambiente doméstico. ${ }^{27,28}$

O presente estudo observou que $20,66 \%$ das violências eram praticadas em pessoas idosas com deficiência; sabe-se, entretanto, que a condição de vulnerabilidade também favorece a invisibilidade na malha social, contribuindo, portanto, com a subnotificação dos casos. ${ }^{29}$

Achados na literatura afirmam que, comumente, a pessoa idosa é vítima de diversos tipos de violência simultaneamente. ${ }^{30}$ Mesmo sendo difícil a identificação e notificação dos tipos de violência praticada contra as pessoas idosas pelas barreiras encontradas para que os envolvidos façam a revelação do caso, no presente artigo a violência física foi a mais prevalente, com 44,96\% dos casos, seguida da negligência/ abandono, com 29,64\%. Isso possivelmente se explicaria pelo fato de esses tipos de violências serem detectáveis mais facilmente, como mostra a literatura. ${ }^{19,31}$ 
Os achados do presente artigo mostram que a violência contra a pessoa idosa ocorre predominantemente em suas residências, tendo os filhos do sexo masculino como os principais perpetradores para as vítimas de ambos os sexos. Uma explicação para esse fato seria sugerida por alguns estudos, quando afirmam que a qualidade das relações familiares anterior ao estado de dependência da pessoa idosa, ou seja, os vínculos sentimentais em relação ao cuidador, determina a forma positiva ou negativa da reação diante da situação agindo com gratidão ou desprezo. 19,32-34

Segundo Day, ${ }^{27}$ a violência intrafamiliar frequentemente vem acompanhada do segredo e da negação, dificultando a chegada dos casos ao conhecimento da Justiça. Para Lopes, ${ }^{35}$ o reconhecimento da violência intrafamiliar pode auxiliar na minimização dos danos gerados em cada família e interromper a continuidade desse ciclo. De acordo com Pasinato et al., ${ }^{36}$ a elevada frequência de violência intrafamiliar condiz com a ausência de políticas públicas que auxiliem as famílias no cuidado às pessoas idosas.

A construção de redes de apoio efetivas para o atendimento integral das pessoas idosas requer o comprometimento do Estado e da sociedade civil. ${ }^{37}$ Para que as políticas funcionem no sentido de oferecer cobertura às necessidades da pessoa idosa, deve-se entender o sistema de proteção. Deve-se considerar a importância de o profissional de saúde ter consciência da notificação nos casos de violência, assim como do encaminhamento correto para os setores responsáveis, dentro ou fora do setor de saúde.

$\mathrm{Na}$ presente casuísta, destaca-se que $68,18 \%$ do total dos casos notificados foram encaminhados para o setor de saúde e 36,36\% para outros setores componentes da rede de atendimento às pessoas em situação de violência. Esse fato mostra uma articulação, ainda que tênue, das instituições de proteção, uma vez que é fundamental o reconhecimento do fato para a interrupção do ciclo de violência e desencadeamento de ações de proteção à pessoa idosa previsto no Estatuto do Idoso.?

Algumas limitações inerentes aos estudos que utilizam dados secundários de notificação, como o subregistro, devem ser consideradas na análise dos dados, por não retratarem toda a magnitude da violência sofrida pela pessoa idosa. De acordo com os dados apresentados, o estudo mostra que a violência contra as pessoas idosas continua ainda subnotificada, mas observou-se incremento das notificações pelos serviços de saúde do Recife, passando de 1,46\% em 2009 para 3,37\% em 2012. Na presente pesquisa, o elevado percentual de ignorados nas categorias analisadas pode ter prejudicado a elaboração fidedigna do perfil da violência contra pessoas idosas no Recife, destacando-se as categorias referentes à escolaridade da vítima, o agressor e o sexo do agressor, com 80,17\%, 43,96\% e 54,13\% dos casos, respectivamente.

\section{CONCLUSÃO}

Os resultados apresentados nesta pesquisa demonstraram que o perfil epidemiológico mais frequente da violência contra a pessoa idosa na cidade do Recife-PE é semelhante ao apresentado pela literatura nacional e internacional, segundo os quais as vítimas são do sexo feminino, pardas e sofreram violência física em sua residência perpetrada pelo filho do sexo masculino. A violência contra a pessoa idosa é um fenômeno de notificação recente no Brasil; com isso, sugerese que sejam feitos mais estudos que abordem a temática, pois, por intermédio dos dados epidemiológicos, o planejamento de estratégias e a implementação de políticas serão viabilizados.

O processo de envelhecimento é um fenômeno atual, e a violência contra a pessoa idosa é um fato real. A dependência funcional da pessoa idosa e a fragilidade das relações familiares a tornam mais vulnerável à violência. Dessa forma, espera-se que essas informações sejam utilizadas na elaboração de medidas 
educativas, de mobilização social e elaboração de ações multidisciplinares e intersetoriais para a construção de uma rede de proteção à pessoa idosa, visando romper o silêncio e intensificar as notificações, com o intuito de impactar positivamente na redução dos casos de violência.

\section{REFERÊNCIAS}

1. Sanches APRA, Lebrão ML, Duarte YAO. Violência Contra Idosos: uma questão nova? Saúde Soc 2008;17(3):90-100.

2. Minayo MCS. Violência contra idosos: o avesso do respeito à experiência e à sabedoria. Brasília: Secretaria Especial dos Direitos Humanos; 2004.

3. Gawryszewski VP, Jorge MHPM, Koizumi MS. Mortes e internações por causas externas entre os idosos no Brasil: o desafio de integrar a saúde coletiva e a tensão individual. Rev Assoc Med Bras 2004;50(1):97-103.

4. Oliveira SC, Leite AC, Monteiro LCA, Pavarini SCI. Violência em idosos após a aprovação do Estatuto do Idoso: revisão integrativa. Rev Eletrônica Enferm 2012;14(4):974-82.

5. Brasil. Ministério da Saúde. Lei no 8.842, de 04 de janeiro de 1994. Dispõe sobre a Política Nacional do Idoso, cria o Conselho Nacional do Idoso e dá outras providências. Diário Oficial da União. 05 de jan 1994. p. 77.

6. Brasil. Política Nacional do idoso. Decreto $n^{\circ} 1948$ de 03 de julho de 1996. Regulamenta a Lei no 8.842, de 4 de janeiro de 1994, que dispõe sobre a Política Nacional do Idoso, e dá outras providências. Diário Oficial da União. 04 de jul de 1996. p. 12277.

7. Silva EAO, Lacerda AMGM. A violência e os maus-tratos contra a pessoa idosa. Fragmentos Cult 2007;17(3/4):239-55.

8. Brasil. Ministério da Saúde. Estatuto do idoso: Lei Federal no 10.741, de 01 de outubro de 2003. Brasília, DF: Secretaria Especial dos Direitos Humanos; 2004.

9. Florêncio MVL, Ferreira MO Filha, Sá LD. A violência contra o idoso: dimensão ética e política de uma problemática em ascensão. Rev Eletr Enferm 2007;9(3):847-57.

10. Organização Mundial de Saúde. Relatório mundial sobre violência e saúde. Genebra: Organização Mundial de Saúde; 2002.

\section{AGRADECIMENTOS}

À Secretaria Municipal de Saúde do Recife-PE, e em especial ao apoio dado pelos profissionais da Divisão de Vigilância de Doenças e Agravos Não Transmissíveis e Promoção à Saúde.
11. Silva MCM. Descortinando a violência sexual em crianças e adolescentes: análise da invisibilidade do problema sobre a ótica epidemiológica e clínica-legal [tese]. Recife: Fundação Oswaldo Cruz, Centro de Pesquisas Aggeu Magalhães; 2009.

12. Guimarães RM, Cunha UGV. Sinais e sintomas

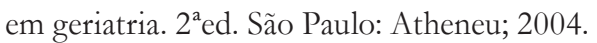

13. Brasil. Ministério da Saúde. Portaria n 737 MS/GM, de 16 de maio de 2001. Política nacional de redução da morbimortalidade por acidentes e violências. Brasília, DF: Ministério da Saúde; 2001.

14. De Sousa DJ, White HJ, Soares LM, Nicolosi GT, Cintra FA, D’Elboux MJ. Maus-tratos contra idosos: atualização dos estudos brasileiros. Rev Bras Geriatr Gerontol 2010;13(2):321-8.

15. Gawryszewski VP, Silva MMA, Malta DC, Mascarenhas MDM, Costa VC, Matos SG, et al. A proposta da rede de serviços Sentinela como estratégia da vigilância de violências e acidentes. Ciênc Saúde Coletiva 2006;11Supl:1269-78.

16. Brasil. Lei no 12.461, de 26 de julho de 2011. Altera a Lei $n^{\circ} 10.741$, de $1^{\circ}$ de outubro de 2003 , para estabelecer a notificação compulsória dos atos de violência praticados contra o idoso atendido em serviço de saúde. Diário Oficial da União. 27 jul 2011. p. 2.

17. Saliba O, Garbin CAS, Garbin AJI, Dossi AP. Responsabilidade do profissional de saúde sobre a notificação de casos de violência doméstica. Rev Saúde Pública 2007;41(3):472-7.

18. Brasil. Ministério da Saúde, Secretaria de Vigilância em Saúde. Viva: instrutivo de notificação de violência doméstica, sexual e outras violências. Brasília, DF: Ministério da Saúde; 2011.

19. Minayo MCS. Violência contra idosos: relevância para um velho problema. Cad Saúde Pública 2003;19(3):783-91. 
20. Queiroz ZPV, Lemos NFD, Ramos LR. Fatores potencialmente associados à negligência doméstica entre idosos atendidos em programa de assistência domiciliar. Ciênc Saúde Coletiva 2010;15(6): 2815-24.

21. Souza ER, Minayo MCS. Inserção do tema violência contra a pessoa idosa nas políticas públicas de atenção à saúde no Brasil. Ciên Saúde Coletiva 2010;15(6):2659-68.

22. Cavalcanti MLT, Souza ER. Percepções de gestores e profissionais de saúde sobre a atenção aos idosos vítimas de violências no município do Rio de Janeiro (RJ, Brasil). Ciên Saúde Coletiva 2010;15(6):2699-708.

23. Mello ALSF, Moysés SJ. Análise diagnóstica do atendimento pré-hospitalar para acidentes e violências contra idosos em Curitiba (PR, Brasil). Ciên Saúde Coletiva 2010;15(6):2709-18.

24. Souza ER. Masculinidade e violência no Brasil: contribuições para a reflexão no campo da saúde. Ciênc Saúde Coletiva 2005;10(1):59-70.

25. Santos ACPO, Silva CA, Carvalho LS, Menezes MR. A construção da violência contra idosos. Rev Bras Geriatr Gerontol 2007;10(1):1-10.

26. Mascarenhas MDM, Silva MMA, Malta DC, Moura L, Macário EM, Gawryszewski VP, et al. Perfil epidemiológico dos atendimentos de emergência por violência do Sistema de Serviços Sentinelas de Vigilância de Violências e Acidentes (Viva) - Brasil, 2006. Epidemiol Serv Saúde 2009;18(1):17-28.

27. Day VP, Telles LEB, Zoratto PH, Azambuja MRF, Machado DA, Silveira MB, et al. Violência doméstica e suas diferentes manifestações. Rev Psiquiatr 2003;25(1 supl):9-21.

28. Gonçalves CA. Idosos: abuso e violência. Rev Port Clín Geral 2006; 22(6):739-45.
29. Ferreira WB. Vulnerabilidade à violência sexual no contexto da escola inclusiva: reflexão sobre a invisibilidade da pessoa com deficiência. Rev Electr Iberoam Calid Eficác Cambio Educ 2008;6(2):1-18.

30. Minayo MC, Souza ER. As múltiplas mensagens da violência contra idosos. In: Minayo MC, Souza ER, organizadores. Violência sob o olhar da saúde: a infrapolítica da contemporaneidade brasileira. Rio de Janeiro: Fiocruz; 2003. p. 223-42.

31. Bradley M. Elder abuse. Br Med J 1996;7056(313):548-50.

32. Williamson GM, Shaffer DR. The family relationships in late life project. psychol Aging 2001;16(2):217-26.

33. Mascarenhas MDM, Andrade SSCA, Neves ACM, Pedrosa AAG, Silva MMA, Malta DC, et al. Violência contra a pessoa idosa: análise das notificações realizadas no setor saúde - Brasil, 2010. Ciênc Saúde Coletiva 2012;17(9):2331-41.

34. Abath MB. Violência contra a pessoa idosa: o que revelam os laudos periciais do Instituto de Medicina Legal [dissertação]. Recife: Universidade Federal de Pernambuco; 2009.

35. Lopes MJM, Paixão DY. Saúde da família: história, práticas e caminhos. Porto Alegre: Universidade Federal do Rio Grande do Sul; 2007.

36. Pasinato MT, Camarano AA, Machado L. Idosos vítimas de maus-tratos domésticos: estudo exploratório das informações levantadas nos serviços de denúncia. Rio de Janeiro: IPEA; 2006.

37. Veras R. Vida plena sem violência na maturidade: a busca contemporânea. Ciênc Saúde Coletiva 2010;15(6):2671-73. 